
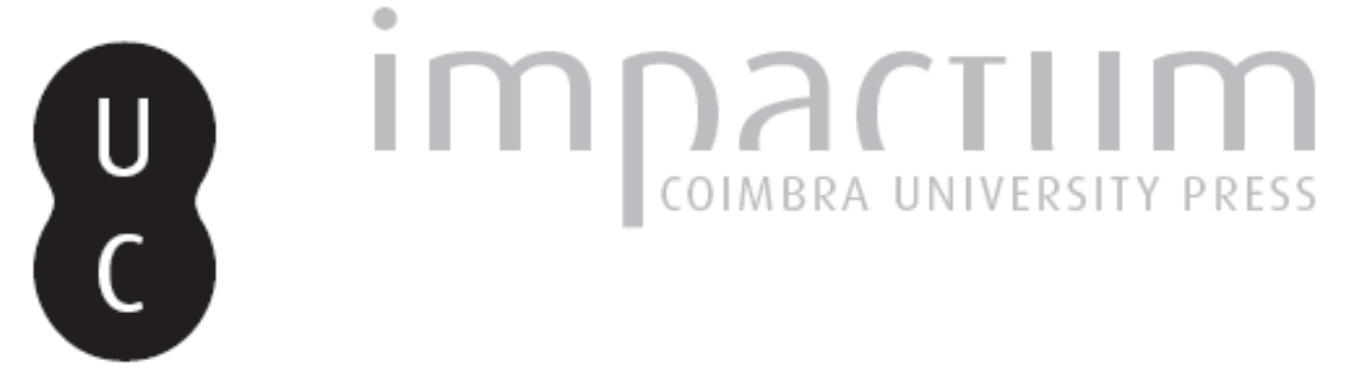

\title{
[Recensão a] Jaime Gouveia, A Quarta Porta do Inferno. A Vigilância e Disciplinamento da Luxúria Clerical no Espaço Luso-Americano (1640-1750)
}

\author{
Autor(es): $\quad$ Braga, Isabel Drumond
}

Publicado por: Imprensa da Universidade de Coimbra

URL persistente:

URI:http://hdl.handle.net/10316.2/38206

DOI:

DOI:http://dx.doi.org/10.14195/0870-4147_46_26

Accessed : $\quad$ 26-Apr-2023 15:02:42

A navegação consulta e descarregamento dos títulos inseridos nas Bibliotecas Digitais UC Digitalis, UC Pombalina e UC Impactum, pressupõem a aceitação plena e sem reservas dos Termos e Condições de Uso destas Bibliotecas Digitais, disponíveis em https://digitalis.uc.pt/pt-pt/termos.

Conforme exposto nos referidos Termos e Condições de Uso, o descarregamento de títulos de acesso restrito requer uma licença válida de autorização devendo o utilizador aceder ao(s) documento(s) a partir de um endereço de IP da instituição detentora da supramencionada licença.

Ao utilizador é apenas permitido o descarregamento para uso pessoal, pelo que o emprego do(s) título(s) descarregado(s) para outro fim, designadamente comercial, carece de autorização do respetivo autor ou editor da obra.

Na medida em que todas as obras da UC Digitalis se encontram protegidas pelo Código do Direito de Autor e Direitos Conexos e demais legislação aplicável, toda a cópia, parcial ou total, deste documento, nos casos em que é legalmente admitida, deverá conter ou fazer-se acompanhar por este aviso.

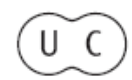




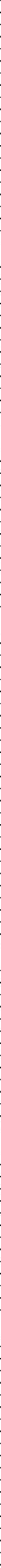


Jaime Gouveia, A Quarta Porta do Inferno. A Vigilância e Disciplinamento da Luxúria Clerical no Espaço Luso-Americano (1640-1750). Lisboa: Chiado Editora, 2015, 602 p.

A obra de Jaime Gouveia constitui a tese de doutoramento do autor, orientada por Bartolomé Yun Casalilla e por José Pedro Paiva, e defendida no Instituto Universitário Europeu de Florença. O título, bastante sugestivo, foi inspirado numa frase de um sermão de Afonso Maria de Liguori (1696-1787), futuro santo, já que foi canonizado no século XIX, pelo Papa Gregório XVI. O napolitano, que é considerado o padroeiro dos confessores, entendeu que havia quatro portas para o Inferno: o ódio, a blasfémia, o furto e a desonestidade ligada aos comportamentos sexuais. Ora, numa obra que analisa e explica os comportamentos sexuais desviantes do clero e os mecanismos empreendidos para os vigiar e disciplinar, a escolha parece de todo acertada.

Como em qualquer trabalho de investigação, nesta obra, Jaime Ricardo optou por enunciar um conjunto de problemas aos quais tentou dar resposta, partindo de hipóteses várias, designadamente, e de entre outros: teriam ou não, na época, uma dimensão endémica os comportamentos sexuais desviantes do clero? Casos e percentagens eram diferentes em Portugal e no Brasil? Como agiram as autoridades dos dois lados do Atlântico? Como se explicam as diferenças entre o volumoso número de denúncias e o baixo número de processos? $\mathrm{E}$ fê-lo a partir de uma perspetiva comparativa, neste caso entre Portugal e mais especificamente a diocese de Coimbra, e o Brasil, em especial Minas Gerais e, secundariamente, Maranhão, numa cronologia que, sem ser limitativa, se fixou preferencialmente entre 1640 e 1750.

Ao longo da obra desmistificaram-se ideias feitas e repetidas sem qualquer fundamento documental que, não obstante, têm chegado ao presente com algum impacto em certas correntes historiográficas. Referimo-nos, em especial, ao entendimento de que o território brasileiro seria um espaço de desregrada prevaricação sexual do clero sem semelhança com o que acontecia na metrópole. Passo a passo, através da recolha, análise e interpretação de fontes depositadas em arquivos e bibliotecas diversos, em especial o Arquivo Eclesiástico de Mariana, o Arquivo da Universidade de Coimbra e o Arquivo Nacional da Torre do Tombo, mas também no Arquivo Diocesano de Lamego, no Arquivo Histórico Ultramarino, no Arquivo Público do Estado do Maranhão, no Arquivo da Santa Casa da Misericórdia da Baía, no Archivio Segreto Vaticano, na Biblioteca Nacional de Portugal, na Biblioteca Pública de Évora e no Instituto Histórico e Geográfico Brasileiro, Jaime Gouveia foi, de forma totalmente fundamentada, refutando ideias vãs, colocando novas hipóteses, demonstrando 
através de exemplos qualitativos e de estatísticas, que a realidade fora diferente do que se tem veiculado.

A obra começou com um aprofundado estado da questão em várias áreas, o que tem total cabimento pois na investigação cruzaram-se vários interesses e temáticas, a saber: controlo social, Reforma, Contra-Reforma, confessionalização, disciplinamento social, sexualidade, reforma espiritual da Cristandade, papel da confissão, desvios clericais e dispositivos de vigilância e de disciplinamento dos mesmos e, finalmente, estudos sobre a articulação dos poderes. Esclarecidas as escolhas espácio-temporais e a metodologia, definidos e clarificados os conceitos, feito um elenco crítico dos trabalhos já realizados e colocados os problemas e as hipóteses, o autor avançou para a explanação das teses.

Ao estudar a sexualidade clerical, o autor entrou na área dos comportamentos sexuais desviantes praticados pelos homens da Igreja, dando continuidade ao que já antes fizera na sua tese de mestrado, posteriormente publicada, sob o título O Sagrado e o Profano em Choque no Confessionário. O Delito de Solicitação no Tribunal da Inquisição. Portugal 1551-1700 (Coimbra: Palimage, 2011). Ao longo de mais de 600 páginas, Jaime Gouveia desmontou várias teorias infundadas, designadamente: a luxúria clerical da colónia brasileira entendida como o resultado da inexistência, inoperância ou tolerância intencional dos mecanismos de vigilância e de disciplinamento, vinculadas aos pretensos interesses da população branca que visava a procriação para povoar o território; a ideia da existência de um clero inferior e imoral no Brasil, que levaria a aceitar os referidos comportamentos desviantes, uma vez que seria preferível um grupo prevaricador à não existência de homens da Igreja na colónia; o entendimento no sentido de se defender que as políticas de vigilância e de castigo do clero tinham sido diferentes no Portugal metropolitano e no Brasil colonial; a teoria de que o clero atuante no Brasil era inapto e vinculado à política mais do que à religião; e, finalmente, a perspetiva responsável por se defender que o Santo Ofício da Inquisição silenciava os comportamentos clericais desviantes, o que explicaria o baixo número de casos julgados pelo Tribunal. Seria assim? A análise da documentação e a ótica comparativa demonstraram o contrário.

A documentação em estudo, em alguns casos lacunar, caso das visitas pastorais e dos processos do auditório eclesiástico, muitas vezes abundante, caso das denúncias e dos processos do Santo Ofício, revela os cuidados com a vigilância dos comportamentos desviantes, quer através dos mecanismos verticais quer dos horizontais. Assim, a colaboração entre os bispos e a Inquisição dos dois lados do Atlântico (referimo-nos quer às pessoas quer às estruturas físicas das dioceses), na continuação de trabalhos de José Pedro Paiva; 
os próprios comportamentos que eram objeto de atenção, quer pelas autoridades quer pelos leigos e até por outros membros do clero, conduzem-nos ao problema da compreensão dos mecanismos de denúncia aliados à interiorização da disciplina, neste caso dos preceitos católicos, conhecidos por membros de vários grupos sociais. Por outro lado, o papel da confissão e o facto de se negar a absolvição caso não se fossem delatar certos comportamentos, designadamente a solicitação e a sodomia, evidenciam a relevância deste sacramento como arma para controlar os fiéis e como um apoio significativo ao Tribunal do Santo Ofício, que assim conseguia apurar mais casos pertencentes à sua esfera. Menos relevante terá sido a oratória sagrada, mesmo assim os sermões não deixavam de informar a população sobre os bons e os maus comportamentos, o que as ajudava a identificar os problemas.

Tudo isto e muito mais permite verificar as semelhanças entre a sexualidade do clero na metrópole e no Brasil, quer no que se refere aos autores dos atos quer às vítimas, compreensivelmente mais variadas do ponto de vista étnico, no que se refere à colónia. E permite também apurar a ação e mais dificilmente a eficácia do disciplinamento do clero, apesar da interação das justiças eclesiásticas, civis e inquisitoriais. Ressalve-se que, no caso do Santo Ofício, a jurisdição sobre o pecado nefando de sodomia e sobre a solicitação alicerçava-se na presunção da defesa da "má doutrina" por parte do sacerdote e não nas transgressões morais e sexuais em si mesmas. A diferença entre denúncias e processos - visível em todos os delitos sob alçada do Santo Ofício e não apenas nos casos em estudo bem como as próprias denúncias e auto delações revelam-nos traços marcantes das maneiras de estar e de agir do passado, pensemos na justificação do recurso à sodomia imperfeita para evitar a gravidez, ou nas denúncias enquanto reflexos da conflituosidade entre as pessoas, o que implicou a adoção de critérios para a acreditação das testemunhas, baseados no género e na proeminência social. Enfim, termino com as palavras de Jaime Gouveia: "a quarta porta do Inferno, tendo em conta o sentido que Afonso Maria Liguori lhe atribui, tanto esteve aberta na colónia como escancarada na metrópole" (p. 528). Eis que de forma consistente se refutaram erros e exageros, eis que se avançou no conhecimento.

ISABEL DRUMOND BRAGA Faculdade de Letras da Universidade de Lisboa Email: isabeldrumondbraga@hotmail.com 